Ciência Florestal, Santa Maria, v. 21, n. 4, p. 629-639, out.-dez., 2011

ISSN 0103-9954

\title{
ESTRUTURA FITOSSOCIOLÓGICA DA VEGETAÇÃO ARBÓREA DO PARQUE NATURAL MUNICIPAL DE SANTO ÂNGELO, SANTO ÂNGELO, RS
}

\author{
PHYTOSSOCIOLOGICAL STRUCTURE OF ARBOREAL VEGETATION IN NATURAL \\ MUNICIPAL PARK OF SANTO ÂNGELO, SANTO ÂNGELO, RS
}

\author{
Alexandre Hüller ${ }^{1}$ Adelita Rauber ${ }^{2}$ Mario Sergio Wolski ${ }^{3}$ \\ Nelson Lopes de Almeida ${ }^{4}$ Silvia Raquel Scherer Wolski ${ }^{5}$
}

\begin{abstract}
RESUMO
O presente trabalho foi realizado no Parque Natural Municipal de Santo Ângelo (RS), pertencente à Prefeitura Municipal de Santo Ângelo, com o objetivo de avaliar a composição florística e estrutura fitossociológica da floresta, em uma área de 13 hectares. Para tanto, foram utilizadas 12 parcelas de tamanho 10 × 20 m distribuídas sistematicamente na área, nas quais foram medidos e identificados todos os indivíduos com DAP maior ou igual a $10 \mathrm{~cm}$. Os resultados obtidos foram analisados e processados com o uso do programa FITOANÁLISE, calculando-se os parâmetros fitossociológicos de densidade, dominância, frequência, valor de importância, valor de cobertura, índice de diversidade de Shannon H' e índice de Morisita. Foram encontradas 35 espécies, pertencentes a 30 gêneros e 21 famílias, das quais branquilho (Sebastiania commersoniana (Baill.) L. B. Sm. \& Downs), açoita-cavalo (Luhea divaricata Mart), mariapreta (Diatenopterix sorbifolia Radlk) e canela-preta (Nectandra megapotamica Spreng.) foram as que apresentaram maior representatividade nos parâmetros fitossociológicos do componente arbóreo desta floresta. As espécies com maior Valor de Importância (VI) foram açoita-cavalo (Luhea divaricata Mart) com 50,53; branquilho (Sebastiania commersoniana (Baill.) com 46,24; maria-preta (Diatenopterix sorbifolia Radlk) com 26,93; canela-preta (Nectandra megapotamica Spreng.) com 20 e farinha-seca (Machaerium stipitatum Vogel) com 16,64. Já na estrutura vertical da floresta, Luehea divaricata apresentou maiores valores no estrato superior e Sebastiania commersoniana Baill. nos estratos médio e inferior.
\end{abstract}

Palavras-chave: componente arbóreo; diversidade florística; Floresta Estacional Decidual.

\section{ABSTRACT}

The present work was performed in the Natural Municipal Park of Santo Ângelo (RS) owned by the City Government of Santo Ângelo, the objective was to evaluate the floristic composition and the phytosociological structure of the forest, in an area with 13 hectares. Twelve units samples of size 10 x 20 m systematically distributed in the area were used, in which these unit samples were measured and identified all individuals with DAP greater than or equal to $10 \mathrm{~cm}$. The results were analyzed and processed with the use of the software FITOANÁLISE, calculating the phytosociological parameters of density, dominance, frequency, value of importance, value of coverage, diversity Shannon H' index and Morisita index. 35 species were found, belonging to 30 genera and 21 families, of which (Sebastiania commersoniana (Baill.) L. B. Sm.

1. Biólogo, Especialista em Ciências Ambientais, Mestrando em Ciência e Tecnologia de Sementes, Universidade Federal de Pelotas, Av. Inhacorá, 49, Apto. 304, Bairro Centro, CEP 98900-000, Santa Rosa (RS). alexandrehuller@sema.rs.gov.br

2. Bióloga, Especialista em Ciências Ambientais, Tv. Jose Mendes, 317, Apto. 102, Bairro COHAB, CEP 98800000, Santo Ângelo (RS). adelita_rauber@yahoo.com.br

3. Geógrafo, MSc., Professor Titular do Departamento das Engenharias e Ciência da Computação, Universidade Regional Integrada do Uruguai e das Missões, Campus Santo Ângelo, Rua Universidade das Missões, 464, Bairro Dorneles, CEP 98802-470, Santo Ângelo (RS). mwolski@urisan.tche.br

4. Engenheiro Florestal, Coordenador Técnico da Associação de Reflorestamento de Santo Ângelo, Rua Sete de Setembro 755, Bairro Centro, CEP 98801-680, Santo Ângelo (RS).nelson.1@terra.com.br

5. Engenheira Florestal, MSc., Professora do Curso de Pós-graduação em Ciências Ambientais, Universidade Regional Integrada do Uruguai e das Missões, Campus Santo Ângelo, Rua Marechal Floriano, 1430, Bairro Centro, CEP 98801-640, Santo Ângelo (RS). srscherer@sol.psi.br

Recebido para publicação em 18/05/2009 e aceito em 1/02/2010 
\& Downs), açoita-cavalo (Luhea divaricata Mart), maria- preta (Diatenopterix sorbifolia Radlk) e canela preta (Nectandra megapotamica Spreng.) were the ones with greater in phyto-sociological parameters from the tree components of forest. The species with the greatest value of importance (VI) were açoita-cavalo (Luhea divaricata Mart) with 50,53; branquilho (Sebastiania commersoniana Baill.) with 46,24; mariapreta (Diatenopterix sorbifolia Radlk) with 26,93, canela preta (Nectandra megapotamica Spreng.) with 20 and farinha-seca (Machaerium stipitatum Vogel) with 16,64. The forest vertical structure Luhea divaricata showed higher values in the upper stratum and Sebastiania commersoniana Baill in middle and lower strata.

Keywords: tree components; floristic diversity; Seasonal Deciduous Forest.

\section{INTRODUÇÃO}

A cobertura florestal no Rio Grande do Sul, que inicialmente correspondia a cerca de $40 \%$ do território, encontra-se reduzida atualmente a $17,53 \%$, segundo dados do inventário florestal contínuo do RS realizado em 2001 (UFSM/SEMARS, 2001). A perda dos habitats florestais é a maior ameaça à diversidade biológica, levando espécies e mesmo comunidades inteiras a ponto de extinção (PRIMACK \& RODRIGUES, 2001). A ocupação intensiva do solo para atividades agropecuárias e a retirada de produtos da floresta, especialmente madeira e lenha, ainda são os principais fatores que levam à deterioração e à redução da vegetação nativa (COELHO, 2000).

A fragmentação florestal pode interferir na conservação das espécies da fauna e flora local e na distribuição da variabilidade genética entre e dentro das populações, sendo que esta situação é ainda mais agravada em áreas que se localizam perto de áreas urbanizadas ou em processo de urbanização devido à pressão antrópica que as cidades exercem sobre estes fragmentos florestais remanescentes (FISZON et al., 2003). A fragmentação florestal tende a gerar populações reduzidas e isoladas reprodutivamente. Com isso, espera-se um nível mais elevado de endogamia, o que pode gerar depressão endogâmica (FRANKHAM et al., 2002).

Por outro lado, estas áreas remanescentes de florestas localizadas próximas aos centros urbanos cumprem uma função extremamente importante na manutenção do equilíbrio ambiental, principalmente relacionado à manutenção da qualidade do ar, do solo e dos recursos hídricos e o clima local, sendo que quando degradadas geram consequências negativas para a sociedade como um todo (SILVERSTON e LONGHI, 1988).

Em Santo Ângelo, restam poucos fragmentos florestais localizados próximos à zona urbana, resistindo a esta pressão antrópica ocasionada pelo crescimento populacional nas áreas urbanas. Dentre estes fragmentos, o Parque Natural Municipal de Santo Ângelo se destaca pela área representativa de aproximadamente 13 ha e por sua localização, fazendo parte da mata ciliar do rio Ijuí, que é o principal rio da região.

O Parque Natural Municipal de Santo Ângelo foi criado no ano de 2006, pela Lei Municipal $\mathrm{n}^{\circ} 2.965$ de 18 de abril de 2006, que unificou os três parques que existiam (Parque das Américas, Parque Poncho Verde e Parque do Sol das Águias). A denominação "Parque Natural Municipal de Santo Ângelo" foi escolhida para atender a uma orientação da Secretaria Estadual de Meio Ambiente (SEMA), com o propósito de incluí-lo no Sistema Estadual de Unidades de Conservação (SEUC).

Apesar do avanço obtido com a criação de uma unidade de conservação no município, ainda faltam ações concretas de conservação e recuperação ambiental nesta área. Para que isso ocorra, é indispensável um conhecimento detalhado de toda a área através da realização de um diagnóstico ambiental eficiente. Uma boa forma de iniciar estes estudos é obter um conhecimento mais detalhado da estrutura fitossociológica da floresta que cobre a maior parte da área do Parque. Estes dados, geralmente, são um bom indicativo do estado de conservação e capacidade de recuperação das comunidades vegetais locais, podendo-se usar estas informações como base para o planejamento, elaboração e implantação de estratégias visando à preservação e à recuperação desta floresta, principalmente através da elaboração de um plano de manejo do parque. Na Região das Missões percebese um déficit muito grande de informações desta natureza e assim o trabalho também pode contribuir para a ampliação dos conhecimentos florísticos e fitossociológicos da vegetação ocorrente na região.

Somente a partir da década de 70 é que os estudos florísticos, fitossociológicos e ecológicos de matas ciliares foram intensificados no Brasil, particularmente nos Estados de São Paulo e Minas Gerais, com o intuito de fornecer subsídios

Ci. Fl., v. 21, n. 4, out.-dez., 2011 
para proteção e enriquecimento de matas ciliares (RODRIGUES, 2001 apud SOUZA et al., 2003). Atualmente, estes estudos são desenvolvidos mais frequentemente e aproveitados para proporcionar elementos reais para ações de planejamento e recuperação ambiental, uma vez que com esta avaliação é possível diagnosticar a estrutura fitossociológica de uma floresta.

Para a conservação das matas remanescentes e seu manejo adequado, Kageyama (1987) recomenda a adoção de práticas compatíveis com a composição florística e estrutura das populações, considerando-se principalmente a forma de ocorrência das espécies, o modo de reprodução e o relacionamento das mesmas com o ambiente, onde todas as interações estão presentes.

A simples descrição fisionômica, com a listagem das espécies encontradas, e a apresentação de perfis-diagramas, não descreve satisfatoriamente a estrutura da vegetação, pois fornece apenas um indicativo da aparência total. Parâmetros numéricos, tais como os valores de abundância, dominância e frequência, visam caracterizar numericamente esta estrutura, motivo pelo qual assumem grande importância (KELLMAN, 1975 apud SILVESTRON e LONGHI, 1988).

Verifica-se, então, a necessidade da realização de estudos que retratem a realidade de florestas desta região, no que tange à florística e sua estrutura, para que estas informações possam ser úteis na elaboração e planejamento de ações que objetivem a conservação ou mesmo a recuperação da formação florestal original, procurando retratar a sua diversidade ao máximo (WATZLAWICK et al., 2005).

Assim, este trabalho tem por objetivo avaliar a estrutura fitossociológica da área do Parque Natural Municipal, gerando os subsídios necessários para a elaboração de um plano de ações e posteriormente um plano de manejo para preservar e recuperar de forma efetiva esta área.

\section{MATERIAIS E MÉTODOS}

\section{Caracterização da área de estudo}

A área de estudo está localizada no Parque Natural Municipal de Santo Ângelo, entre as coordenadas geográficas de $28^{\circ} 19^{\prime} 17^{\prime \prime}$ de latitude sul e $54^{\circ} 15^{\prime} 52^{\prime \prime}$ de longitude oeste, com uma variação de altitude de 195 até 240 m (Figura 1).

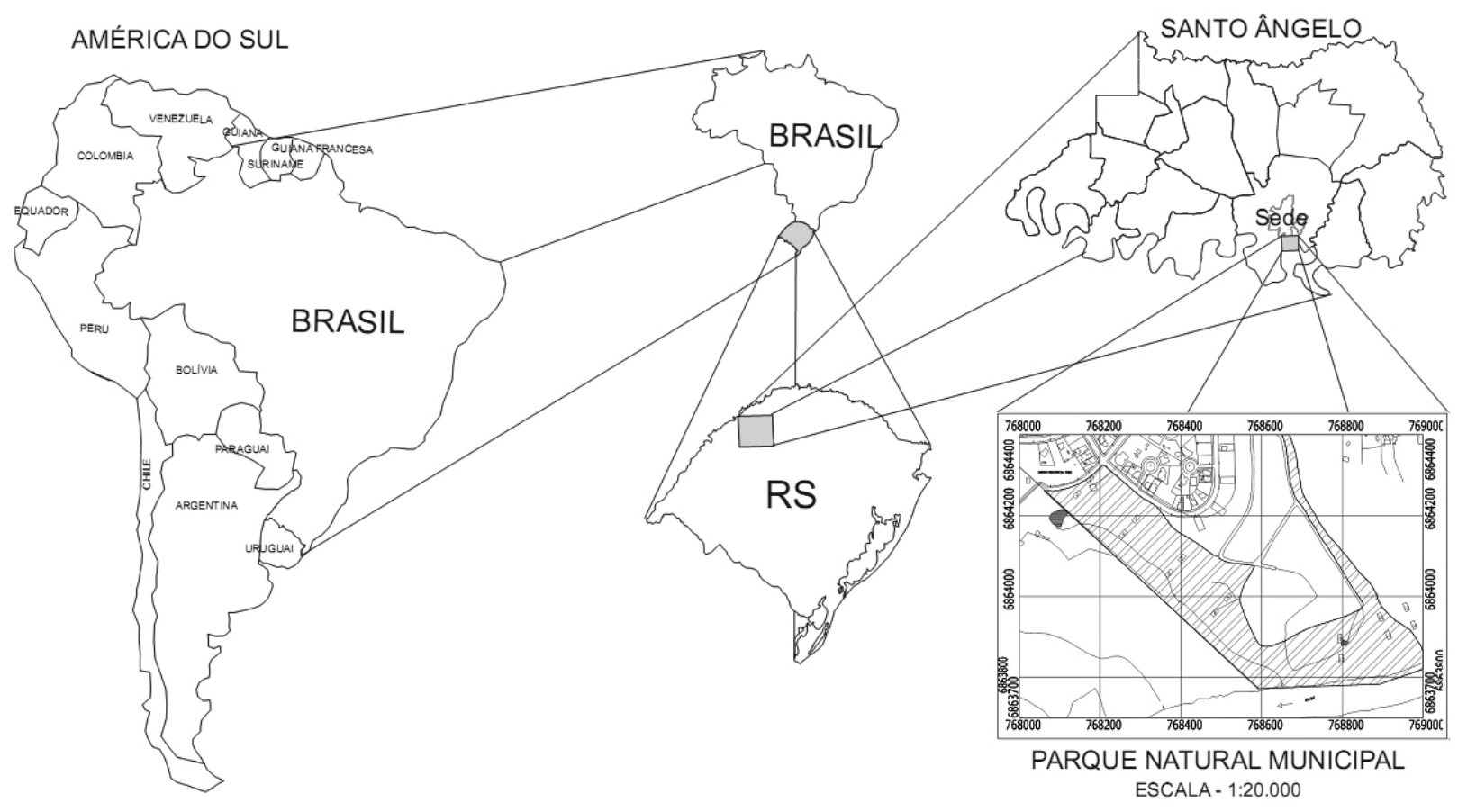

FIGURA 1: Situação e localização da área de estudo (Parque Natural Municipal de Santo Ângelo), município de Santo Ângelo/RS.

FIGURE 1: Situation and location of the studied area (Natural Municipal Park of Santo Ângelo), City of the Santo Ângelo, RS state. 
A vegetação da área de estudo faz parte da Floresta Estacional Decidual, abrangendo parte da mata ciliar do rio Ijuí. De acordo com IBGE (1992), este tipo de formação apresenta grandes áreas descontínuas, que se dividem em quatro formações distintas, chamadas de: Floresta Estacional Decidual Aluvial; Floresta Estacional Decidual de Terras Baixas; Floresta Estacional Decidual Submontana e Floresta Estacional Decidual Montana, sendo que a formação da Floresta Estacional Decidual Aluvial ocorre quase exclusivamente nas bacias dos rios do Estado do RS e na região de estudo, observase já uma transição deste tipo de vegetação com as formações vegetais típicas dos campos sulinos, mais ao sul e a oeste.

O clima na região é subtropical úmido, do tipo Cfa, conforme a classificação de Köppen (MORENO, 1961). A temperatura média anual é de $21,8^{\circ} \mathrm{C}$ e a precipitação pluviométrica anual de 1734,5 mm (IRDeR, 2004).

O município de Santo Ângelo localiza-se na encosta Ocidental do Planalto Médio Rio-Grandense, Região Noroeste do Estado, Zona Fisiográfica das Missões. O tipo de solo predominante é o Latossolo Vermelho Distroférrico Típico (STRECK et al., 2002), originado de basalto e arenito, de textura argilosa, relevo ondulado, substrato basáltico da unidade de mapeamento Santo Ângelo. A Bacia Hidrográfica referente ao local é a do rio Ijuí, que inclusive margeia a área de estudo.

\section{Metodologia utilizada}

O levantamento fitossociológico foi realizado empregando-se o método de parcelas fixas, mediante a utilização de 12 parcelas com dimensões de $10 \mathrm{~m}$ de largura por $20 \mathrm{~m}$ de comprimento, totalizando $200 \mathrm{~m}^{2}$ de superfície, distribuídas sistematicamente na área de mata nativa do Parque, conforme Figura 1.

A marcação das parcelas foi apoiada na base cartográfica planialtimétrica, com o lançamento das parcelas em faixas, pelo método dos transectos. Para a locação no terreno, foi confeccionada uma planta de locação para cada parcela. As parcelas foram materializadas a campo utilizando equipamentos topográficos (Estação Total) e aplicado o método de coordenadas polares.

Foi estabelecida uma distância de 150 $\mathrm{m}$ entre as parcelas. Em cada parcela, foram inventariados todos os exemplares com diâmetro à altura do peito (DAP) maior ou igual a $10 \mathrm{~cm}$ e registrados os seguintes dados: espécie vegetal,
DAP, altura total, qualidade do fuste e posição sociológica.

Os parâmetros fitossociológicos calculados foram os de densidade, frequência e dominância, absolutas e relativas, valor de cobertura, valor de importância, índice de diversidade de Shannon e Índice de Morisita (MUELLER-DOMBOIS e ELLENBERG apud BARDDAL et al. (2004) e SCHNEIDER e FINGER (2000)). Os parâmetros da estrutura vertical da floresta, com a análise da posição sociológica em três estratos diferentes - inferior, médio e superior -, também foram avaliados.

Os dados coletados foram processados com o uso do programa FITOANÁLISE elaborado por Carvalho Júnior et al. (1999). As espécies foram determinadas nas famílias reconhecidas pelo APG III (2009). A identificação das espécies foi feita a campo, sendo que os indivíduos não identificados tiveram material botânico coletado para posterior identificação com auxílio de bibliografia e de profissionais da área botânica.

Os levantamentos foram realizados nos meses de maio a outubro do ano de 2008.

\section{RESULTADOS E DISCUSSÃO}

A suficiência amostral foi testada pela curva espécie-área conforme Figura 2, regularmente utilizada em levantamentos fitossociológicos. Ocorreu uma estabilização parcial da curva espécie-área entre 2400 e $2600 \mathrm{~m}^{2}$ da área amostral e houve um acréscimo no número de espécies até $2400 \mathrm{~m}^{2}$, quando a curva estabilizou. Considerando até $10 \%$ de erro, as 12 parcelas amostradas foram suficientes para representar a composição florística do fragmento, levando-se em consideração que, em florestas naturais, a tendência à estabilização é suficiente para representar a vegetação, considerando-se ainda que, com o aumento da área amostrada, podem ocorrer novas espécies (LONGHI et al., 1999).

Foram encontrados 164 indivíduos com DAP acima de $10 \mathrm{~cm}$, dos quais 10 estavam mortos, na área estudada. Estes indivíduos estão distribuídos em 35 espécies, pertencentes a 30 gêneros e 21 famílias botânicas (Tabela 1). Cabe salientar que devido à pequena área de floresta estudada e a consequente pequena área amostral, algumas espécies podem não ter aparecido no levantamento. Porém a riqueza florística é semelhante à encontrada por Rosa et al. (2008), que encontraram 27 espécies, 


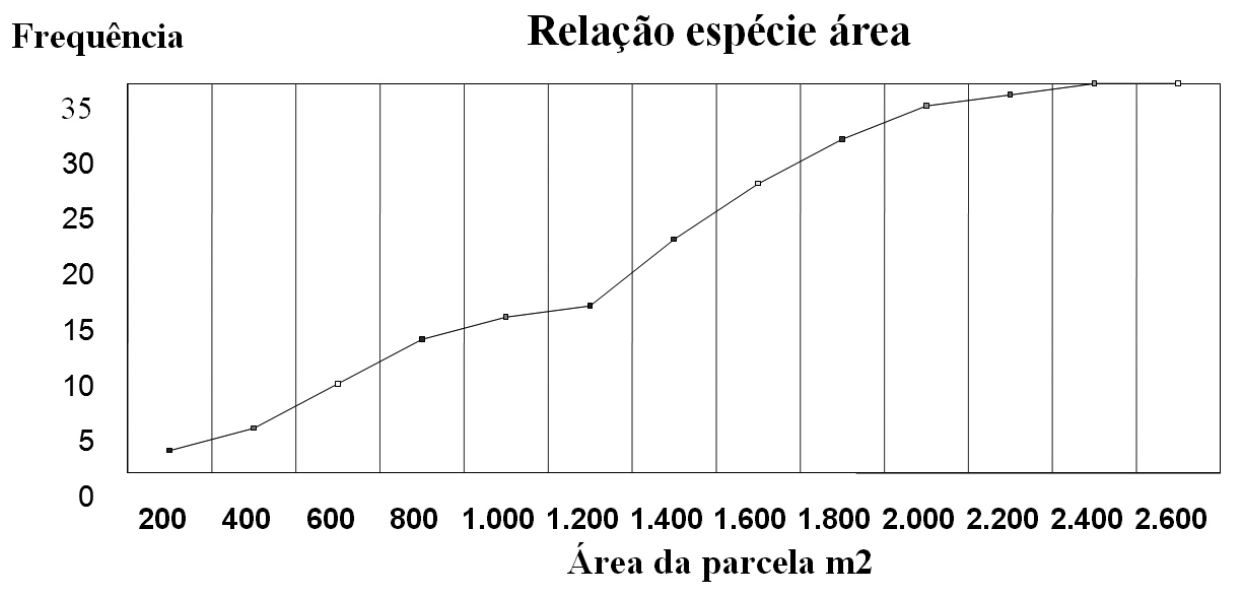

FIGURA 2: Gráfico demonstrando a suficiência amostral testada pela curva espécie-área do levantamento fitossociológico no Parque Natural Municipal de Santo Ângelo, município de Santo Ângelo/ RS.

FIGURE 2: Graph showing sample sufficiency tested by species area curve in the phyto-sociological Natural Municipal Park of Santo Ângelo, City of the Santo Ângelo, RS state.

de 24 gêneros e 18 famílias botânicas, na Reserva Ecológica Capão de Tupanciretã, no município de Tupanciretã - RS, em uma área de 8 ha.

Para a avaliação da distribuição espacial das espécies, foi calculado o Índice de Morisita, que mede o grau de dispersão das espécies na área (SCHNEIDER e FINGER, 2000). Os valores encontrados indicaram que 54,28\% das espécies têm distribuição uniforme, 37,14\% distribuição aleatória e para 8,58\% a distribuição é agregada.

A família mais representativa da área, quanto ao número de espécies, foi a Myrtaceae, com cinco diferentes espécies, seguida por Sapindaceae, com quatro espécies, Anacardiaceae, com três espécies e ainda Boraginaceae, Euphorbiaceae, Fabaceae e Lauraceae, com duas espécies cada uma. A expressiva participação de Myrtaceae na composição florística da área estudada coincide com diversos estudos florísticos realizados em diferentes formações florestais no Sul do Brasil (NASCIMENTO et al. 2001; NETO et al. 2002; JURINITZ e JARENKOW 2003; BUDKE et al. 2004), destacando a importância da família nestas comunidades.

As 15 famílias restantes são representadas cada uma por uma espécie e um gênero diferente. Quanto ao número de indivíduos, foi a família Euphorbiaceae que apresentou o maior valor, com 30 indivíduos pertencentes a quatro espécies, seguida por Sapindaceae, com 35 indivíduos pertencentes a duas espécies, Malvaceae, com 20 indivíduos pertencentes a apenas uma espécie e Lauraceae com 17 indivíduos pertencentes a duas espécies.

A partir dos resultados obtidos, foi projetada uma densidade total por área de 683 indivíduos por hectare. Este número é superior aos valores encontrados no Parque Estadual do Turvo, no município de Derrubadas - RS, também localizado em área de ocorrência da Floresta Estacional Decidual. Em levantamento realizado em 1992, Vasconcellos et al. (1992) encontraram 546,5 árvores por ha e Dias et al. (1992) encontraram 412 árvores por ha.

Do total de indivíduos amostrados, 7,31\% foram árvores mortas, indicando uma densidade de 49 árvores por hectare, resultado este mais elevado do que o encontrado por Dias et al. (1992); Vasconcellos et al. (1992), que encontraram 2,21\% e $4,43 \%$, respectivamente, em seus estudos no Parque Estadual do Turvo. Hack et al. (2005) também encontraram 1,85\% numa floresta localizada no município de Jaguari - RS. Levando-se em conta que a área do Parque localiza-se em área urbanizada e sofre constantemente ações de degradação, e como a retirada de lenha pelos moradores é bastante comum, é de se supor que o número de indivíduos mortos seja superior aos valores encontrados no levantamento. Isso pode estar correlacionado com eventos climáticos, como fortes ventos na região, gerando como consequência abertura de clareiras na floresta e consequentemente danos em algumas árvores. 
TABELA 1: Relação das espécies arbóreas amostradas no Parque Natural Municipal de Santo Ângelo, em Floresta Estacional Decidual, Santo Ângelo, RS, 2008.

TABLE 1: List of the arboreal species sampled in the Natural Municipal Park of Santo Ângelo, in Seasonal Deciduous Forest, Santo Ângelo, RS state, 2008.

\begin{tabular}{|c|c|c|}
\hline Família & Nome Científico & Nome Vulgar \\
\hline Anacardiaceae & Lithraea molleoides (Vell.) Engl. & Aroeira-brava \\
\hline Anacardiaceae & Schinus polygamus (Cav.) Cabrera & Aroeira-de-espinho \\
\hline Anacardiaceae & Schinus terebinthifolius Raddi & Aroeira-vermelha \\
\hline Apocynaceae & Peschiera australis (Müll. Arg.) Miers & Cobrina \\
\hline Asteraceae & Gochnatia polymorpha (Less.) Cabrera & Cambará \\
\hline Cordiaceae & Cordia americana $\mathrm{L}$. & Guajuvira \\
\hline Cordiaceae & Cordia trichotoma Vell. & Louro \\
\hline Ebenaceae & Diospyros inconstans Jacquin & Fruta-de-jacú \\
\hline Euphorbiaceae & Sebastiania commersoniana (Baill.) Smith \& Downs & Branquilho-comum \\
\hline Euphorbiaceae & Sebastiania brasiliensis Spreng. & Branquilho-leiteiro \\
\hline Fabaceae & Machaerium stipitatum Vogel & Farinha-seca \\
\hline Fabaceae & Lonchocarpus campestris Mart. ex Bentham & Pau-canzil \\
\hline Fabaceae & Acacia caven (Molina) Molina & Espinilho \\
\hline Laminaceae & Vitex megapotamica (Sprengel) Moldenke & Tarumã \\
\hline Lauraceae & Ocotea puberula Nees & Canela-guaicá \\
\hline Lauraceae & Nectandra megapotamica (Spreng.) Mez & Canela-preta \\
\hline Malvaceae & Luehea divaricata Mart. & Açoita-cavalo \\
\hline Myrtaceae & Eugenia involucrata DC. & Cerejeira \\
\hline Myrtaceae & Campomanesia xanthocarpa Berg & Guabiroba \\
\hline Myrtaceae & Eugenia uniflora L. & Pitangueira \\
\hline Myrtaceae & Campomanesia guazumifolia (Camb.) Berg & Sete-capotes \\
\hline Myrtaceae & Eugenia pyriformis Camb. & Uvaia \\
\hline Polygonaceae & Rupretchia laxiflora Meissner & Marmeleiro-do-mato \\
\hline Rosaceae & Prunus myrtifolia (L.) Urban. & Pessegueiro-do-mato \\
\hline Rutaceae & Zanthoxylum roifolium Lam. & Mamica-de-cadela \\
\hline Sapindaceae & Matayba elaeagnoides Radlk. & Camboatá-branco \\
\hline Sapindaceae & Cupania vernalis Camb. & Camboatá-vermelho \\
\hline Sapindaceae & Allophylus edulis (A. St.-Hilaire) Radlk. & Chal-chal \\
\hline Sapindaceae & Diatenopteryx sorbifolia Radlk. & Maria-preta \\
\hline Sapotaceae & Pouteria salicifolia (Spreng.) Radlk. & Sarandi-mata-olho \\
\hline Solanaceae & Brunfelsia uniflora Pohl (D. Don) & Primavera \\
\hline Styracaceae & Styrax leprosus Hook. \& Arn. & Carne-de-vaca \\
\hline Rhamnaceae & Hovenia dulcis Thunberg & Uva-do-japão \\
\hline Cannabaceae & Celtis tala Gill. & Esporão de galo \\
\hline
\end{tabular}

Ci. Fl., v. 21, n. 4, out.-dez., 2011 
Conforme mostra a Tabela 2, as espécies com maior número de indivíduos presentes na área de estudo foram Sebastiania commersoniana, com 33 indivíduos $(20,12 \%$ do total); Luehea divaricata, com 20 indivíduos (12,19\%), Nectandra megapotamica com 14 indivíduos $(8,53 \%)$ e Cupania vernalis e mortas com 12 indivíduos cada uma $(7,31 \%$ cada).

TABELA 2: Parâmetros fitossociológicos da vegetação arbórea do Parque Natural Municipal de Santo Ângelo, Santo Ângelo, RS, 2008.

TABLE 2: Phytosociological parameters in the arboreal vegetation in the Natural Municipal Park of Santo Ângelo, Santo Ângelo, RS, 2008.

\begin{tabular}{|c|c|c|c|c|c|c|c|c|c|}
\hline Nome científico & $\mathrm{N}$ & DA & DR & DoA & DoR & FA & FR & IVI & IVC \\
\hline Sebastiania commersoniana & 33 & 126,92 & 21,42 & 5,93 & 11,39 & 84,65 & 13,41 & 46,24 & 32,8 \\
\hline Luehea divaricata & 20 & 76,92 & 12,98 & 15,11 & 29,00 & 53,84 & 8,53 & 50,53 & 41,99 \\
\hline Nectandra megapotamica & 14 & 53,84 & 9,09 & 2,50 & 4,81 & 38,46 & 6,09 & 20,00 & 13,90 \\
\hline Cupania vernalis & 12 & 46,15 & 7,79 & 1,39 & 2,66 & 38,46 & 6,09 & 16,55 & 10,46 \\
\hline Morta & 12 & 46,15 & 7,79 & 0,75 & 1,45 & 46,14 & 7,2 & 16,2 & 9,24 \\
\hline Diatenopteryx sorbifolia & 7 & 26,92 & 4,54 & 9,12 & 17,51 & 30,76 & 4,87 & 26,93 & 22,00 \\
\hline Allophylus edulis & 6 & 23,07 & 3,89 & 0,81 & 1,57 & 38,46 & 6,09 & 11,56 & 5,46 \\
\hline Celtis tala & 6 & 23,07 & 3,89 & 0,29 & 0,57 & 30,76 & 4,87 & 9,34 & 4,46 \\
\hline Lonchocarpus campestris & 5 & 19,23 & 3,24 & 0,48 & 0,93 & 23,07 & 3,65 & 7,83 & 4,17 \\
\hline Matayba elaeagnoides & 5 & 19,21 & 3,24 & 0,82 & 1,58 & 30,76 & 4,87 & 9,70 & 4,82 \\
\hline Prunus myrtifolia & 4 & 15,38 & 2,59 & 0,89 & 1,72 & 15,38 & 2,43 & 6,76 & 4,32 \\
\hline Vitex megapotamica & 4 & 15,38 & 2,59 & 0,89 & 1,71 & 15,38 & 2,43 & 6,75 & 4,31 \\
\hline Ocotea puberula & 3 & 11,53 & 1,94 & 0,29 & 0,56 & 15,38 & 2,43 & 4,94 & 2,51 \\
\hline Pouteria salicifolia & 3 & 11,53 & 1,94 & 1,29 & 2,48 & 7,69 & 1,22 & 5,64 & 4,43 \\
\hline Schinus terebinthifolius & 3 & 11,53 & 1,94 & 0,11 & 0,21 & 23,07 & 3,65 & 5,82 & 2,16 \\
\hline Styrax leprosus & 3 & 11,53 & 1,94 & 0,11 & 0,21 & 7,69 & 1,22 & 3,38 & 2,16 \\
\hline Eugenia uniflora & 3 & 11,53 & 1,94 & 0,17 & 0,32 & 15,38 & 2,43 & 4,71 & 2,27 \\
\hline Sebastiania brasiliensis & 2 & 7,69 & 1,29 & 0,51 & 0,99 & 15,38 & 2,43 & 4,72 & 2,28 \\
\hline Machaerium stipitatum & 2 & 7,69 & 1,29 & 7,36 & 14,12 & 7,69 & 1,22 & 16,64 & 15,42 \\
\hline Lithraea molleoides & 2 & 7,69 & 1,29 & 0,86 & 1,65 & 15,38 & 2,43 & 5,39 & 2,95 \\
\hline Cordia americana & 1 & 7,69 & 1,29 & 0,86 & 1,65 & 15,38 & 2,43 & 5,39 & 2,95 \\
\hline Ruprechtia laxiflora & 1 & 3,84 & 0,64 & 0,12 & 0,23 & 7,69 & 1,22 & 2,10 & 0,88 \\
\hline Schinus polygamus & 1 & 3,84 & 0,64 & 0,07 & 0,14 & 7,69 & 1,22 & 2,01 & 0,79 \\
\hline Acacia caven & 1 & 3,84 & 0,64 & 0,58 & 1,11 & 7,69 & 1,22 & 2,98 & 1,76 \\
\hline Zanthoxylum rhoifolium & 1 & 3,84 & 0,64 & 0,03 & 0,06 & 7,69 & 1,22 & 1,92 & 0,70 \\
\hline Brunfelsia uniflora & 1 & 3,84 & 0,64 & 0,04 & 0,08 & 7,69 & 1,22 & 1,95 & 0,73 \\
\hline Hovenia dulcis & 1 & 3,84 & 0,64 & 0,13 & 0,25 & 7,69 & 1,22 & 2,12 & 0,90 \\
\hline Campomanesia guazumifolia & 1 & 3,84 & 0,64 & 0,12 & 0,24 & 7,69 & 1,22 & 2,10 & 0,89 \\
\hline Campomanesia xanthocarpa & 1 & 3,84 & 0,64 & 0,22 & 0,42 & 7,69 & 1,22 & 2,23 & 1,07 \\
\hline Cordia trichotoma & 1 & 3,84 & 0,64 & 0,24 & 0,46 & 7,69 & 1,22 & 2,33 & 1,11 \\
\hline Peschiera australis & 1 & 3,84 & 0,64 & 0,03 & 0,07 & 7,69 & 1,22 & 1,94 & 0,72 \\
\hline Diospyros inconstans & 1 & 3,84 & 0,64 & 0,37 & 0,72 & 7,69 & 1,22 & 2,59 & 1,37 \\
\hline Eugenia involucrata & 1 & 3,84 & 0,64 & 0,03 & 0,06 & 7,69 & 1,22 & 1,92 & 0,70 \\
\hline Eugenia pyriformis & 1 & 3,84 & 0,64 & 0,17 & 0,33 & 7,69 & 1,22 & 2,19 & 0,98 \\
\hline Gochnatia polymorpha & 1 & 3,84 & 0,64 & 0,08 & 0,17 & 7,69 & 1,22 & 2,04 & 0,82 \\
\hline TOTAL & 164 & 592,3 & 100 & 52,1 & 100 & 630,7 & 100 & 300 & 200 \\
\hline
\end{tabular}

Em que: $\mathrm{N}$ = número de indivíduos; $\mathrm{DA}=$ densidade absoluta; $\mathrm{DR}=$ densidade relativa; $\mathrm{DoA}$ = dominância absoluta; $\mathrm{DoR}=$ densidade relativa; $\mathrm{FA}=$ frequência absoluta; $\mathrm{FR}=$ frequência relativa; $\mathrm{IVI}$ = índice do valor de importância; $\mathrm{IVC}=$ índice do valor de cobertura. 
A floresta avaliada apresentou um índice de Shannon H' de 3,07. Para as formações florestais pertencentes à Floresta Estacional Decidual este valor pode ser considerado elevado, indicando uma boa diversidade de espécies na área de estudo. Longhi et al. (2000) encontraram um valor de 3,213 em estudo realizado também em um fragmento de Floresta Estacional Decidual, em Santa Maria, RS.

Nenhuma espécie esteve presente em todas as parcelas, o que mostra a variabilidade encontrada ao longo da área de estudo, talvez explicada pela heterogeneidade da área e da floresta, que em partes representa a mata ciliar do rio Ijuí, e em outras representa uma transição floresta/campo.

$\mathrm{Na}$ avaliação da estrutura horizontal da floresta estudada, destacam-se as espécies que apresentaram o maior Valor de Importância (VI): Luhea divaricata com 50,53, Sebastiania commersoniana com 46,24, Diatenopteryx sorbifolia com 26,93, Nectandra megapotamica com 20,00 e Machaerium stipitatum com 16,64. O VI permite uma caracterização da espécie no conglomerado total da floresta e seu valor é alavancado, geralmente, por indivíduos com dimensões diamétricas maiores e pela grande frequência de uma espécie (ROSA et al., 2008), como também pela sua densidade.

Para o valor de cobertura (VC), calculado a partir das dimensões dos indivíduos amostrados, os dados mostraram a mesma sequência de espécies apresentadas no valor de importância.

A espécie Luehea divaricata, embora não seja a espécie mais abundante da floresta (20 indivíduos amostrados), é a mais dominante, com $29,00 \%$ da área basal total das espécies. Isto se deve às grandes dimensões de seus indivíduos. De acordo com Marchiori (2000), Luehea divaricata pode atingir $30 \mathrm{~m}$ de altura e $100 \mathrm{~cm}$ de diâmetro. Trata-se de uma espécie com dispersão em todas as regiões do estado, sendo particularmente frequente ao longo dos rios e áreas úmidas, considerada como uma das árvores características e emergentes das matas de galeria (REITZ et al., 1988). Ainda segundo os mesmos autores, é muito comum em matas semidevastadas, nas capoeiras e capoeirões.

Já a espécie Sebastiania commersoniana, que foi a espécie mais abundante da floresta, com 33 indivíduos encontrados no estudo, apresentou valor de dominância mais baixo $(11,39 \%)$, mas obteve, por outro lado, o segundo maior valor de VC e VI, principalmente pelo fato da grande ocorrência desta espécie na área de estudo. Segundo
Lorenzi (1992), esta espécie ocorre geralmente em agrupamentos, chegando a formar populações quase puras.

A espécie Nectandra megapotanica apresentou o terceiro maior valor de VI e VC e de frequência, com 6,09\%, assim como Cupania vernalis. Para Reitz et al. (1988), N. megapotamica pertence ao pequeno grupo arbóreo que se encontra em ótima vitalidade no interior da floresta densa e desenvolvida, onde ao lado das arvores adultas e velhas constata-se uma vigorosa regeneração junto com árvores medianamente desenvolvidas.

A espécie Diatenopteryx sorbifolia apresentou o quarto maior VI e VC, e apenas o sétimo maior valor de frequência, com um valor de 4,87, mostrando também uma distribuição considerável na área total da floresta. Para Reitz et al. (1988) trata-se de uma espécie bastante frequente em áreas ao longo das encostas, com distribuição irregular e descontínua. É frequente em florestas abertas e, sobretudo, nas clareiras abertas pelo homem ou por tempestades.

Quanto à estrutura vertical da floresta, apresentada na Tabela 3, observa-se que a espécie Luehea divaricata domina o estrato superior com $29,63 \%$ dos indivíduos, seguida por Nectandra megapotamica e Diatenopteryx sorbifolia com $14,81 \%$ dos indivíduos amostrados neste estrato.

Sebastiania commersoniana foi a espécie mais representativa dos estratos médio e inferior, com valores de $22,2 \%$ e $57,69 \%$, respectivamente. Rosa et al. (2008) também encontraram a espécie Sebastiania commersoniana como a mais representativa do estrato inferior, sugerindo esta espécie como pertencente ao sub-bosque. É considerada uma espécie que predomina em florestas aluviais e das matas de galeria, onde muitas vezes se torna abundante e dominante, em todas as regiões fisiográficas do RS, afirmam Reitz et al. (1988).

A espécie Allophylus edulis alcançou a oitava colocação no VI desta floresta. Trata-se de uma espécie com capacidade para habitar o sub-bosque (BARDDAL et al., 2004) e o estrato médio das florestas (REITZ et al. apud ROSA et al. (2008)). Na área estudada, apresentou valores consideráveis em ambos os estratos.

Ainda com relação ao estrato médio da floresta, a espécie Luehea divaricata também apresentou valores significativos (13,58\%), seguida de Cupania vernalis com $(11,11)$ e Nectandra megapotamica com 8,64\%. 
TABELA 3: Estrutura sociológica vertical do Parque Natural Municipal de Santo Ângelo, Santo Ângelo, RS, 2008.

TABLE 3: Vertical sociological structure in the Natural Municipal Park of Santo Ângelo, Santo Ângelo, RS, 2008.

\begin{tabular}{|c|c|c|c|c|c|c|c|c|c|c|}
\hline \multirow{3}{*}{ Nome científico } & \multicolumn{9}{|c|}{ Estratos Arbóreos } & \multirow[b]{3}{*}{$\mathrm{S}$} \\
\hline & \multicolumn{3}{|c|}{ Superior } & \multicolumn{3}{|c|}{ Médio } & \multicolumn{3}{|c|}{ Inferior } & \\
\hline & $\mathrm{N}$ & $\%$ esp. & $\%$ estr. & $\mathrm{N}$ & $\%$ esp. & $\%$ estr. & $\mathrm{N}$ & $\%$ esp. & $\%$ estr. & \\
\hline Allophylus edulis & 0,00 & 0,00 & 0,00 & 19,23 & 6,17 & 83,33 & 3,85 & 2,17 & 16,67 & 23,08 \\
\hline Lonchocarpus campestris & 3,85 & 3,70 & 20,00 & 15,38 & 4,94 & 80,00 & 0,00 & 0,00 & 0,00 & 19,23 \\
\hline Luehea divaricata. & 30,77 & 29,63 & 40,00 & 42,31 & 13,58 & 55,00 & 3,85 & 2,17 & 5,00 & 76,92 \\
\hline Matayba elaeagnoides & 0,00 & 0,00 & 0,00 & 19,23 & 6,17 & 100,00 & 0,00 & 0,00 & 0,00 & 19,23 \\
\hline Nectandra megapotamica & 15,38 & 14,81 & 28,57 & 26,92 & 8,64 & 50,00 & 11,54 & 6,52 & 21,43 & 53,85 \\
\hline Ocotea puberula & 0,00 & 0,00 & 0,00 & 7,69 & 2,47 & 66,67 & 3,85 & 2,17 & 33,33 & 11,54 \\
\hline Patagonula americana & 3,85 & 3,70 & 100,00 & 0,00 & 0,00 & 0,00 & 0,00 & 0,00 & 0,00 & 3,85 \\
\hline Pouteria salicifolia & 0,00 & 0,00 & 0,00 & 11,54 & 3,70 & 100,00 & 0,00 & 0,00 & 0,00 & 11,54 \\
\hline Prunus myrtifolia & 0,00 & 0,00 & 0,00 & 3,85 & 1,23 & 25,00 & 11,54 & 6,52 & 75,00 & 15,38 \\
\hline Ruprechtia laxiflora & 0,00 & 0,00 & 0,00 & 3,85 & 1,23 & 100,00 & 0,00 & 0,00 & 0,00 & 3,85 \\
\hline Schinus polygamus & 0,00 & 0,00 & 0,00 & 3,85 & 1,23 & 100,00 & 0,00 & 0,00 & 0,00 & 3,85 \\
\hline Schinus terebinthifolius & 0,00 & 0,00 & 0,00 & 3,85 & 1,23 & 33,33 & 7,69 & 4,35 & 66,67 & 11,54 \\
\hline Sebastiania brasiliensis & 0,00 & 0,00 & 0,00 & 3,85 & 1,23 & 50,00 & 3,85 & 2,17 & 50,00 & 7,69 \\
\hline Sebastiania commersoniana & 0,00 & 0,00 & 0,00 & 69,23 & 22,22 & 54,55 & 57,69 & 32,61 & 45,45 & 126,92 \\
\hline Styrax leprosus & 0,00 & 0,00 & 0,00 & 0,00 & 0,00 & 0,00 & 11,54 & 6,52 & 100,00 & 11,54 \\
\hline Acacia caven & 0,00 & 0,00 & 0,00 & 0,00 & 0,00 & 0,00 & 3,85 & 2,17 & 100,00 & 3,85 \\
\hline Vitex megapotamica & 7,69 & 7,41 & 50,00 & 3,85 & 1,23 & 25,00 & 3,85 & 2,17 & 25,00 & 15,38 \\
\hline Zanthoxylum rhoifolium & 0,00 & 0,00 & 0,00 & 0,00 & 0,00 & 0,00 & 3,85 & 2,17 & 100,00 & 3,85 \\
\hline Brunfelsia uniflora & 0,00 & 0,00 & 0,00 & 0,00 & 0,00 & 0,00 & 3,85 & 2,17 & 100,00 & 3,85 \\
\hline Machaerium stipitatum & 7,69 & 7,41 & 100,00 & 0,00 & 0,00 & 0,00 & 0,00 & 0,00 & 0,00 & 7,69 \\
\hline Hovenia dulcis & 3,85 & 3,70 & 100,00 & 0,00 & 0,00 & 0,00 & 0,00 & 0,00 & 0,00 & 3,85 \\
\hline Campomanesia guazumifolia & 0,00 & 0,00 & 0,00 & 3,85 & 1,23 & 100,00 & 0,00 & 0,00 & 0,00 & 3,85 \\
\hline Campomanesia xanthocarpa & 3,85 & 3,70 & 100,00 & 0,00 & 0,00 & 0,00 & 0,00 & 0,00 & 0,00 & 3,85 \\
\hline Celtis tala & 0,00 & 0,00 & 0,00 & 7,69 & 2,47 & 33,33 & 15,38 & 8,70 & 66,67 & 23,08 \\
\hline Cordia trichotoma & 3,85 & 3,70 & 100,00 & 0,00 & 0,00 & 0,00 & 0,00 & 0,00 & 0,00 & 3,85 \\
\hline Phyllostachys aurea & 0,00 & 0,00 & 0,00 & 0,00 & 0,00 & 0,00 & 3,85 & 2,17 & 100,00 & 3,85 \\
\hline Cupania vernalis & 3,85 & 3,70 & 8,33 & 34,62 & 11,11 & 75,00 & 7,69 & 4,35 & 16,67 & 46,15 \\
\hline Diatenopteryx sorbifolia & 15,38 & 14,81 & 57,14 & 7,69 & 2,47 & 28,57 & 3,85 & 2,17 & 14,29 & 26,92 \\
\hline Diospyros inconstans & 0,00 & 0,00 & 0,00 & 3,85 & 1,23 & 100,00 & 0,00 & 0,00 & 0,00 & 3,85 \\
\hline Eugenia uniflora & 0,00 & 0,00 & 0,00 & 11,54 & 3,70 & 100,00 & 0,00 & 0,00 & 0,00 & 11,54 \\
\hline Eugenia involucrata & 0,00 & 0,00 & 0,00 & 3,85 & 1,23 & 100,00 & 0,00 & 0,00 & 0,00 & 3,85 \\
\hline Eugenia pyriformis & 3,85 & 3,70 & 100,00 & 0,00 & 0,00 & 0,00 & 0,00 & 0,00 & 0,00 & 3,85 \\
\hline Gochnatia polymorpha & 0,00 & 0,00 & 0,00 & 0,00 & 0,00 & 0,00 & 3,85 & 2,17 & 100,00 & 3,85 \\
\hline Lithraea molleoides & 0,00 & 0,00 & 0,00 & 3,85 & 1,23 & 50,00 & 3,85 & 2,17 & 50,00 & 7,69 \\
\hline Soma: & 103,85 & 100 & & 311,54 & 100 & & 176,92 & 100 & & 592,31 \\
\hline
\end{tabular}

Em que: $\mathrm{N}=$ número de indivíduos; \% esp. = percentagem do estrato representada pela espécie; \% estr. = percentagem de indivíduos da espécie que se encontram no estrato. 
No estrato inferior, a espécie Sebastiania commersoniana também domina, com 32,61\%, seguida por Celtis tala com $8,7 \%$ e Prunus myrtifolia e Styrax leprosus, com 6,52\%.

Celtis tala, apesar de conter somente seis indivíduos no estudo, também apresentou valores consideráveis no estrato inferior $(8,7 \%)$, apresentando um bom potencial de regeneração natural nesta área, uma vez que se encontra em estágio de sucessão nesta floresta.

\section{CONCLUSÕES}

O fragmento florestal estudado apresenta um índice de diversidade florística relativamente elevado, semelhante a outros estudos realizados para a região, onde se destacaram principalmente as espécies Sebastiania commersoniana e Luehea divaricata em termos de número de indivíduos amostrados.

Sugere-se, por fim, a orientação de um plano de manejo do Parque, com a implantação de um projeto de recuperação de área degradada e de proteção das áreas de preservação permanente ao longo das margens do rio Ijuí, aproveitando o conhecimento fitossociológico apresentado neste trabalho e motivando novos e mais aprofundados estudos nesta região.

Cabe salientar ainda que em caso de aprofundamento nos estudos e monitoramento das parcelas avaliadas neste estudo será necessário um aumento na área amostral.

\section{REFERÊNCIAS BIBLIOGRÁFICAS}

APG. An update of the Angiosperm Phylogeny Group classification for the orders and families of flowering plants: APG III. Botanical Journal of the Linnean Society, Londres, v. 161, n. 2, p. 105202, Oct. 2009.

BARDDAL, M. L. et al. Fitossociologia do subbosque de uma floresta ombrófila mista aluvial, no município de Araucária, PR. Ciência Florestal, Santa Maria, v. 14, n. 1, p. 35-45, mar./abr. 2004.

BUDKE, J. C. et al. Florística e fitossociologia do componente arbóreo de uma floresta ribeirinha, Passo das Tropas, Santa Maria, RS, Brasil. Acta Botânica Brasílica, v. 18 n.3, p. 581-589, set./dez. 2004.

CARVALHO JUNIOR, L. A. et al. Fitoanálise versão 4.0. Santa Maria: UFSM, 1999. Software COELHO, G. C. A floresta nativa do Noroeste do RS
- questões relevantes para conservação. Caderno de Pesquisa série Botânica, Santa Cruz do Sul, v. 12, n. 1, p. 17-44, 2000.

DIAS, L. L. et al. Levantamento florístico de uma área de mata subtropical no Parque Estadual do Turvo, Tenente Portela, RS. Revista do Instituto Florestal, v. 4, p. 339-346, 1992.

FISZON, J. T. et al. Causas Antrópicas - 03. In: RAMBALDI, D. M.; OLIVEIRA, D. A. S. de (Orgs.). Fragmentação de Ecossistemas: Causas, efeitos sobre a biodiversidade e recomendações de políticas públicas Brasília: MMA/SBF, 2003. p. 6599.

FRANKHAM, R.; BALLOU, J. D.; BRIDGE, D. A. Introduction to Conservation Genetics. Cambridge: Cambridge University Press, 2002.

HACK, C. et al. Análise fitossociológica de um fragmento de floresta estacional decidual no município de Jaguari, RS. Ciência Rural, Santa Maria, v. 12, p. 1083-1091, 2005.

IBGE. Manual Técnico da Vegetação Brasileira. Manuais Técnicos em Geociências. Rio de Janeiro: IBGE, $1991.92 \mathrm{p}$.

IRDeR - Instituto Regional de Desenvolvimento Rural - FIDENE/UNIJUÍ. Estação Pluviométrica, Augusto Pestana/RS, 2004.

JURINITZ, C. F.; JARENKOW, J. A. Estrutura do componente arbóreo de uma floresta estacional na Serra do Sudeste, Rio Grande do Sul, Brasil. Revista Brasileira de Botânica, v. 26, n. 4, p. 475487, dez./out. 2003.

KAGEYAMA, P. Y. Conservação "in situ" dos recursos genéticos de plantas. Série IPEF 35. Curitiba: IPEF, 1987, p.7-40.

LONGHI, S. J. et al. Aspectos florísticos da Floresta Estacional Decidual, às margens do Rio IbicuíMirim no distrito de Boca do Monte, Santa MariaRS. In: CICLO DE ATUALIZAÇÃO FLORESTAL DO CONE-SUL, 1999, Santa Maria. Anais. Santa Maria: UFSM, 1999. p. 254-261.

LONGHI, S. J. et al. Aspectos fitossociológicos de fragmento de floresta estacional decidual, Santa Maria, RS. Ciência Florestal, Santa Maria, v. 10, n. 2, p. 59-74, abr./jun. 2000.

LORENZI, H. Árvores Brasileiras: manual de identificação e cultivo de plantas arbóreas nativas do Brasil. Nova Odessa: Ed. Plantarum, 1992. 352 p.

MARCHIORI, J. N. C. Dendrologia das angiospermas: das bixáceas às rosáceas. Santa Maria: Editora da UFSM, 2000. 240 p.

MORENO, J. A. Clima do Rio Grande do Sul. 
Porto Alegre: Secretaria da Agricultura do Rio Grande do Sul, $1961.73 \mathrm{p}$.

NASCIMENTO, A. R. T.; LONGHI, S. J.; BRENA, D. A. Estrutura e padrões de distribuição espacial de espécies arbóreas em uma amostra de Floresta Ombrófila Mista em Nova Prata, RS. Ciência Florestal, Santa Maria, v. 11, n. 1, p. 105-119, jan./ jun. 2001.

NETO, R. M. R. et al. Análise florística e estrutural de um fragmento de Floresta Ombrófila Mista Montana, situado em Criúva, RS, Brasil. Ciência Florestal, Santa Maria, v. 12, n. 1, p. 29-37, jan./ jun. 2002.

PREFEITURA MUNICIPAL DE SANTO ÂNGELO. Lei Municipal $\mathbf{n}^{0} \mathbf{2} .965 / 2006$. Cria o Parque Natural Municipal de Santo Ângelo.

PRIMACK, R. B.; RODRIGUES, E. Biologia da conservação. Londrina: Ed. Vida, 2001. 327 p.

REITZ, R.; KLEIN, R. M.; REIS, A. Projeto Madeira do Rio Grande do Sul. Porto Alegre: Sudesul, 1988. 525 p.

ROSA, S. F. da; LONGHI, S. J.; LUDWIG, M. P. Aspectos florísticos e fitossociológicos da Reserva Capão de Tupanciretã, Tupanciretã, RS, Brasil. Ciência Florestal, Santa Maria, v. 18, n. 1, p. 1525, jan./mar. 2008.

SCHNEIDER, P. R.; FINGER, C. A. F. Manejo sustentado de florestas inequiâneas heterogêneas.
Santa Maria: UFSM, 2000. 195 p.

SILVERSTON, A.; LONGHI, S. J. Estudo fitossociológico do Parque Municipal "Longines Malinowski" de Erexim - RS. In: CONGRESSO FLORESTAL ESTADUAL, 4., 1988, Nova Prata. Anais... Nova Prata: Prefeitura Municipal de Nova Prata, 1988. p. 527-540. v. 1

SOUZA, J. S. et al. Análise das variações florísticas e estruturais da comunidade arbórea de um fragmento de floresta semidecídua às margens do rio Capivari, Lavras-MG. Revista Árvore, Viçosa, v. 27, n. 2, p. 185-206, mar./abr. 2003.

STRECK, E. V. et al. Solos do Rio Grande do Sul. Porto Alegre, Universidade Federal do Rio Grande do Sul, 2002. $107 \mathrm{p}$.

UFSM/SEMA-RS. Inventário Florestal Contínuo do Rio Grande do Sul. Santa Maria: UFSM/ SEMA-RS, 2001. Disponível em: <http://coralx. ufsm.br/ifcrs/frame.htm>. Acesso em 11/01/2009.

VASCONCELLOS, J. M. O. et al. Fitossociologia de uma área de mata subtropical no parque Estadual do Turvo. Revista do Instituto Florestal, v. 4, p. 252-259, 1992.

WATZLAWICK, L. F. et al. Caracterização da composição florística e estrutura de uma Floresta Ombrófila Mista, no Município de General Carneiro/ PR. Ambiência, Guarapuava, v. 1, n. 2, p. 229-238, maio/ago. 2005. 